\title{
Resonance Fatigue Behaviour of Concretes with Recycled Cement and Aggregate
}

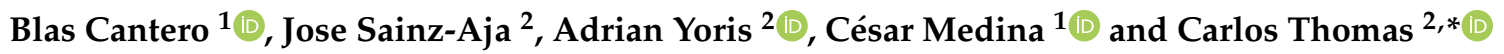 \\ 1 Department of Construction, School of Engineering, University of Extremadura, UEX-CSIC Partnering Unit, \\ Institute for Sustainable Regional Development (INTERRA), 1003 Cáceres, Spain; bcanteroch@unex.es (B.C.); \\ cmedinam@unex.es (C.M.) \\ 2 LADICIM (Laboratory of Materials Science and Engineering), University of Cantabria, E.T.S. de Ingenieros de \\ Caminos, Canales y Puertos, Av/Los Castros, 39005 Santander, Spain; jose.sainz-aja@unican.es (J.S.-A.); \\ adrianyoris84@gmail.com (A.Y.) \\ * Correspondence: thomasc@unican.es
}

Citation: Cantero, B.; Sainz-Aja, J.; Yoris, A.; Medina, C.; Thomas, C. Resonance Fatigue Behaviour of Concretes with Recycled Cement and Aggregate. Appl. Sci. 2021, 11, 5045 https://doi.org/10.3390/ app11115045

Academic Editor: Doo-Yeol Yoo

Received: 5 May 2021

Accepted: 27 May 2021

Published: 29 May 2021

Publisher's Note: MDPI stays neutral with regard to jurisdictional claims in published maps and institutional affiliations.

Copyright: (C) 2021 by the authors. Licensee MDPI, Basel, Switzerland. This article is an open access article distributed under the terms and conditions of the Creative Commons Attribution (CC BY) license (https:// creativecommons.org/licenses/by/ $4.0 /)$.

\begin{abstract}
The huge increase in production of construction and demolition waste (CDW) worldwide is leading to the valorisation of as recycled aggregates. One of the most promising alternatives is its use as a recycled aggregate in the manufacture of structural concrete, which motivates the study of the dynamic behaviour of these materials in order to ensure their suitability for use in elements subjected to dynamic loads. This work evaluated the resonant compressive fatigue behaviour of structural concretes with $25 \%$ or $50 \%$ recycled mixed aggregates, either individually or in combination with $25 \%$ recycled cement of clay-based materials both from CDW. All mixes were subjected to compressive fatigue tests using the accelerated Locati method. Regarding the fatigue limit, the results showed that for all mixes, it was between $30 \%$ and $45 \%$ of the compressive strength. In addition, a correlation was also found between the resonance frequency of the test and the deformation suffered by the specimen. This correlation enabled the estimation of the fatigue limit through a more stable parameter than the strain measured by strain gauges, namely, the resonance frequency. In addition, it was found that the resonance frequency of the test changed as the specimen damage increased. This observation enabled the estimation of the fatigue limit through a more stable parameter than the strain measured by strain gauges, namely, the resonance frequency.
\end{abstract}

Keywords: recycled concrete; resonant fatigue; Locati method; high frequency

\section{Introduction}

Concrete is the most widely used and versatile material in construction [1]. In 2019 $\sim 27 \mathrm{Gt}$ of concrete was consumed worldwide [2], requiring the production of $\sim 19 \mathrm{Gt}$ of natural aggregates (NA) and $\sim 4.1$ Gt of Portland cement [3]. With current urban growth expectations, it is estimated that these quantities could increase by as much as $25 \%$ by 2030 [4]. Meanwhile, this rapid development is leading to a huge increase in construction and demolition waste (CDW) generated during the construction, remodelling and demolition of buildings and infrastructure, currently representing the world's major waste stream.

Consequently, the construction industry must change its current linear "produceuse-dispose" growth model to a more circular growth commitment by adopting actions that ensure sustainable development for concrete without compromising the needs of future generations.

In this context, many countries are promoting policies that include the circular economy model with the aim of prolonging the useful life of structures, reducing the consumption of natural resources and valorizing the waste generated [5]. To this end, the valorisation of CDW as recycled aggregates (RA) in the design of new concretes is an attractive technique that can bring great economic and environmental benefits, given the possibility of obtaining recycled concretes with good mechanical performance [6-8] and 
durability [9-12]. In this line, there are other works that attempt to assess CDW as RA together with new recycled supplementary cementitious material (SCM) (ground granulated blast fume $[13,14]$, ceramics recycled $[15,16]$, concrete recycled $[17,18]$ and biomass waste $[19,20])$ as a partial substitute for cement, providing a double benefit by reducing the consumption of NA and cement, and achieving promising results in the improvement in mechanical and durability performance of concretes made only with CDW.

At present, the fatigue process involving recycled concrete is as yet an inadequately investigated topic [21]. A deeper understanding of this structural behaviour is essential to promote the reincorporation of these new raw materials into the production cycles in the concrete industry.

Fatigue in concrete can be defined as a process of mechanical degradation leading to failure. Due to cyclic loads, crack initiation and propagation within the specimen occur until final failure. However, during the application of the variable loads, a modification of the mechanical parameters of the concrete occurs, progressively varying the structural responses of an element [22]. This behaviour is of great importance in the design of structural elements, such as bridges, airport pavements, roads, marine structures, wind generators, foundations of industrial equipment, etc. Compared to permanent loads, these elements are subjected to a higher number of cyclic loads due to variable loads (transient loads, wind, etc.), and these cyclic loads produce a major reduction in mechanical properties, shortening the service life of this type of structure.

Some researchers have focused their efforts on increasing knowledge about the compressive fatigue behaviour of this new generation of recycled concretes. In this area, Xiao et al. [23] studied the fatigue behaviour of concretes with $100 \%$ recycled coarse aggregates (RCA) ( $>95 \%$ waste concrete). For this purpose, they tested cylindrical specimens in cyclic uniaxial compression tests with a constant minimum fatigue load stress and a frequency of $10 \mathrm{~Hz}$. These authors observed that concretes with $100 \%$ RCA showed fatigue behaviour in three different stages: (i) cyclic creep stage, (ii) creep coupling stage and (iii) fatigue stage, similar to the behaviour pattern of conventional concrete with NA [24]. Thomas et al. $[25,26]$ carried out an extensive experimental programme ( 24 mixes) to study fatigue behaviour of concretes made with RCA $(20 \%, 50 \%$ and $100 \%)$ and different effective water-cement $(\mathrm{w} / \mathrm{c}$ ) eff ratios (from 0.45 to 0.65$)$. In their results, these authors reported that, for same $(\mathrm{w} / \mathrm{c})_{\text {eff }}$, RCA concretes showed a greater reduction in fatigue life than NA concretes. However, concretes with up to $20 \%$ RCA and $(w / c)_{\text {eff }}$ showed fatigue behaviour similar to that of NA concrete.

In general, the reduced fatigue life of RCA concretes can be attributed to: (i) greater numbers of micro-cracks in the RCA produced in the crushing process of concrete waste, which are more easily interconnected as a result of cyclic loading [27] and (ii) larger interfacial transition zones between the cement paste and the RCA, which act as additional weak bonds under cyclic loading [28]. Sainz-Aja et al. [29] observed through microstructural analysis with computer microtomography of RCA concretes subjected to compressive fatigue loading that cracks are mostly generated at the aggregate interfacial transition zone (ITZ) and the edges of the flakier aggregates, propagating through the weaker planes until concrete collapse occurs.

Breccolotti et al. [21] researched the experimental results of Xiao et al. [23] and Thomas et al. [26] in order to improve the understanding of the fatigue behaviour of concretes made with RCA. These authors were able to develop a predictive algorithm to estimate the fatigue behaviour of RCA concrete, knowing the compressive strength, the percentage of NA substitution by RCA and the type of concrete mix, obtaining good agreement between the experimental results and the theoretical prediction. Furthermore, these authors verified that the concretes with RCA complied with the fatigue life predictions calculated according to the Model Code 2010 [30].

Recently, Sainz-Aja et al. [31] combined the accelerated Locati fatigue method with $2 \times 10^{5}$ cycles per step with resonant fatigue, minimising the time and cost of fatigue testing. These authors observed more conservative results in the fatigue behaviour of concretes 
tested at moderate frequency $(10 \mathrm{~Hz})$ than in the case of those tested at high frequency $(\approx 90 \mathrm{~Hz})$, this effect being greater in concretes manufactured with RCA. Moreover, they observed an increase in temperature with increasing frequency, which could reduce the fatigue life of the concrete by increasing creep damage.

From all the research carried out to date, great advances have been made in the knowledge of the fatigue behaviour of concrete with RCA. However, this type of recycled aggregate, in Spain only represents between $30 \%$ and $40 \%$ of CDW [32]. The remainder is represented by mixed recycled aggregates (MRA), the result of jointly crushing used concrete, masonry materials (brick, roof and ceramic tile) and some minor components, including plaster, wood, plastic and glass. MRA are more heterogeneous than RCA, which makes it more difficult to reincorporate them into the concrete production chain. Nevertheless, new scientific contributions are emerging every day that encourage further research in this field, motivated by the possibility of producing concretes with MRA with acceptable mechanical [6,32-34] and durability [10,35-37] results. Furthermore, according to the latest report of the European Commission [38], MRA are the biggest problem within $\mathrm{CDW}$ due to their accumulation in recycling plants.

The recent review by Tang et al. [39] shows that the partial substitution of up to $30 \%$ by weight of recycled clay waste from CDW as SCM in the manufacture of concrete can improve, if the fineness of the waste is adequate, the properties of new concretes incorporating these new SCMs in the cement with respect to conventional concrete, as well as being an effective solution to mitigate the pollutant emissions associated with cement production, with a reduction of up to $8.1 \%$ of cement produced [40].

With this objective, the innovation of this research is to analyse the individual and joint effects of the incorporation of mixed recycled finely ground clay-based waste as SCM to cement (RPW-CDW) and the coarse fraction of mixed recycled aggregates in the study of resonant fatigue behaviour from structural concretes. It purposes to enhance the scientific and technical understanding of the combined use of such waste and contribute to its valorisation. In this context, there are still no research studies on this behaviour with these recycled materials. For this purpose, an experimental programme was designed to carry out resonant fatigue tests using the Locati method with $1 \times 10^{5}$ cycles per step. This technique allowed evaluating the fatigue limit of concretes made with MRA and concretes made with 25\% RPW-CDW and (25-50\%) MRA, finding that the resonance frequency decreases as the damage in the specimen increases. This observation allows estimating the fatigue limit through a more stable parameter than the strain measured by strain gauges, namely the resonance frequency.

Finally, the results of this research will contribute to a better understanding of the resonant fatigue behaviour of this new generation of concretes with MRA and recycled cement from the integral recovery of CDW.

\section{Materials and Methods}

2.1. Materials

\subsubsection{Binders}

The concretes were manufactured with two types of cement: (i) $100 \%$ Ordinary Portland cement (OPC), class 42.5 R according to EN 197-1 [41], without additions, supplied by Lafarge Holcim Cement, Toledo, Spain, and (ii) a recycled cement (OPC-25CDW) composed of $75 \%$ OPC and $25 \%$ recycled ceramic-based waste (bricks, tiles, blocks, etc.) from the crushing and grinding of CDW waste (RWP-CDW). Table 1 shows the chemical composition of RWP-CDW and the resulting OPC-25CDW. This cement is registered by patent $\mathrm{N}^{\circ}$ ES2512065 [42] and can be classified as CEM II/B or CEM IV/A of strength class 42.5 MPa according to EN 197-1 [41]. Similarly, a water-based modified polycarboxylate superplasticiser (SP) admixture with a density of $1.1 \mathrm{~g} / \mathrm{cm}^{3}$ and a solids' content of $20 \%$ from BRYTEN NF furnished by FUCHS Lubricantes was used. 
Table 1. Chemical composition of RWP-CDW and OPC-25CDW XRF analysis.

\begin{tabular}{|c|c|c|c|c|c|c|c|c|c|c|c|c|c|}
\hline \multirow{2}{*}{ Material } & \multicolumn{12}{|c|}{ Chemical Composition (\%wt.) } & \multirow{2}{*}{ LOI } \\
\hline & $\mathrm{SiO}_{2}$ & $\mathrm{Al}_{2} \mathrm{O}_{3}$ & $\mathrm{Fe}_{2} \mathrm{O}_{3}$ & $\mathrm{CaO}$ & $\mathrm{MgO}$ & $\mathrm{SO}_{3}$ & $\mathrm{Na}_{2} \mathrm{O}$ & $\mathrm{K}_{2} \mathrm{O}$ & $\mathrm{TiO}_{2}$ & $\mathrm{P}_{2} \mathrm{O}_{5}$ & $\mathrm{Cl}-$ & $\mathrm{SiO}_{2}{ }^{(1)}$ & \\
\hline OPC & 20.00 & 6.03 & 2.57 & 60.00 & 1.75 & 3.90 & 0.56 & 1.49 & 0.15 & 0.15 & 0.02 & - & 3.26 \\
\hline RWP-CDW & 59.63 & 18.51 & 5.92 & 4.78 & 3.08 & 0.42 & 0.70 & 3.58 & & & - & 35.10 & 2.15 \\
\hline OPC-25CDW & 31.30 & 8.26 & 3.24 & 48.99 & 2.86 & 2.43 & 0.51 & 1.58 & 0.35 & 0.19 & 0.04 & - & 2.66 \\
\hline
\end{tabular}

Note: ${ }^{(1)}$ Reactive.

\subsubsection{Aggregates}

The crushed greywacke natural aggregate used comprised three particle sizes: $0 \mathrm{~mm}$ to $6 \mathrm{~mm}$ (NA-S), $6 \mathrm{~mm}$ to $12 \mathrm{~mm}$ (NA-M) and $12 \mathrm{~mm}$ to 22 (NA-C). The recycled aggregate used, which was supplied by a CDW processing plant located in the Spanish region of Extremadura, had two particle size fractions: $6 \mathrm{~mm}$ to $12 \mathrm{~mm}$ (MRA-M) and $12 \mathrm{~mm}$ to $22 \mathrm{~mm}$ (MRA-C). The composition analysis of recycled aggregates (Table 2), conducted as specified in standard EN 933-11 [43], revealed that the main components were concrete and mortar (47.0-44.0 $\mathrm{wt} \%)$, ceramic $(7.2-10.9 \mathrm{wt} \%)$ and natural stone (44.8-43.8 $\mathrm{wt} \%)$, with others (glass and metals) $(<0.5 \mathrm{wt} \%)$ as minor constituents. On the grounds of these data and the criteria set out in Spain's structural concrete code [44] with its $<95 \mathrm{wt} \%$ $\mathrm{Rcu}(\mathrm{Rcu}=\mathrm{Rc}+\mathrm{Ru})$ content and $>5 \mathrm{wt} \% \mathrm{Rb}$ content, MRA-M and MRA-G qualified for classification as a mixed recycled aggregate.

Table 2. Composition of recycled aggregates.

\begin{tabular}{ccc}
\hline Composition (wt $\%)$ & MRA-M & MRA-G \\
\hline Ceramic & 7.2 & 10.9 \\
Concrete and mortar & 47.0 & 44.0 \\
Natural stone & 44.8 & 43.8 \\
Bituminous & 0.6 & 0.9 \\
Others & 0.4 & 0.4 \\
\hline
\end{tabular}

Note: MRA-M: mixed medium recycled aggregate $(6 / 12 \mathrm{~mm})$; MRA-G: mixed gravel recycled aggregate $(4 / 22 \mathrm{~mm})$.

The particle size distribution and the physical and mechanical properties of all the aggregates used to prepare the concrete mixed are listed in Figure 1 and Table 3, respectively. Due primarily to their higher porosity, the recycled aggregates had a lower density than the natural materials in all particle sizes. The saturated surface dry density was found to lie in the $2.42 \mathrm{Mg} / \mathrm{m}^{3}$ to $2.45 \mathrm{Mg} / \mathrm{m}^{3}$ range. These aggregates also absorbed more water than the NA, a consequence of the adhered mortar and masonry particles present in the new materials, which exhibited absorption percentages within the range of 4.0 to $10 \%$ observed by other authors $[7,17,32]$ for this type of recycled aggregates. As the adhered mortar tended to smooth its sharpest angles, RA had a lower flakiness index than NA. The recycled materials had a higher Los Angeles coefficient than the NA, likewise due to the adhered mortar and the presence of masonry. Here also, the values ranged within the 20 to $40 \%$ reported in the literature for recycled aggregate $[16,33,45]$. Finally, these recycled aggregates complied with the requirements set out in the European standard EN 12620 [46] for use as recycled aggregate in concrete. 


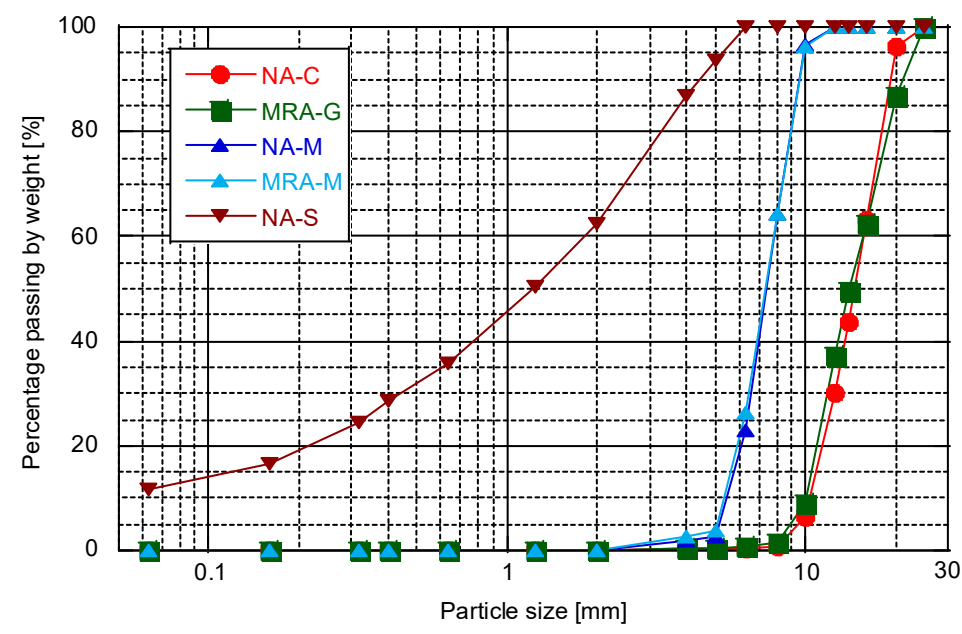

Figure 1. Aggregate particle size distribution. Note: NA-S: natural sand (0/6 mm); NA-M: natural medium gravel (6/12 mm); NA-C: natural coarse gravel (12/22 mm).

Table 3. Physical properties of aggregates.

\begin{tabular}{|c|c|c|c|c|c|c|}
\hline \multirow{2}{*}{ Property } & \multicolumn{6}{|c|}{ Aggregates } \\
\hline & NA-S & NA-M & NA-C & MRA-M & MRA-G & EN 12620 \\
\hline Dry density $\left(\mathrm{g} / \mathrm{cm}^{3}\right)$ [47] & 2.73 & 2.71 & 2.72 & 2.28 & 2.32 & - \\
\hline $\mathrm{SSD}^{(1)}$ density $\left(\mathrm{g} / \mathrm{cm}^{3}\right)$ [47] & 2.76 & 2.74 & 2.74 & 2.42 & 2.45 & - \\
\hline Water absorption $24 \mathrm{~h}(\% \mathrm{wt}$.) [47] & 1.18 & 0.88 & 0.78 & 6.28 & 5.27 & $\leq 5(\leq 7)^{(3)}$ \\
\hline Open Porosity (vol\%) [47] & 3.2 & 2.4 & 1.9 & 14.3 & 12.2 & \\
\hline Los Angeles coefficient (\%wt.) [48] & - & 16 & 18 & 32 & 36 & $<50^{(2)}$ \\
\hline Flakiness index (\%wt.) [49] & - & 21 & 25 & 10 & 10 & $<35$ \\
\hline
\end{tabular}

Note: ${ }^{(1)}$ SSD: Saturated Surface Dry. ${ }^{(2)}$ Concretes with a compressive strength of less than $30 \mathrm{MPa} .{ }^{(3)}$ Mixture of recycled aggregate and natural aggregate.

\subsection{Experimental Procedure}

Table 4 shows the 6 mixes used: a reference concrete $(\mathrm{OPC}+\mathrm{NA})$, a concrete with OPC-25CDW and NA, two concretes with OPC with 25\% and 50\% MRA each and two concretes with OPC-25CDW with 25\% and 50\% MRA replacement each.

Table 4. Identification of manufactured concrete.

\begin{tabular}{cc}
\hline Identification & Description \\
\hline HP & OPC and 100\% NA \\
HR-25 & OPC and 25\% MRA \\
HR-50 & OPC and 50\% MRA \\
HP-R & OPC-25CDW and 100\% NA \\
HRR-25 & OPC-25CDW and 25\% MRA \\
HRR-50 & OPC-25CDW and 50\% MRA \\
\hline
\end{tabular}

Cylindrical specimens of $100 \mathrm{~mm}$ diameter and $200 \mathrm{~mm}$ height were manufactured according to EN 12390-1 [50] for the resonant fatigue tests. These specimens were demoulded after $24 \mathrm{~h}$ and cured at $95 \pm 5 \%$ relative humidity and a constant $20 \pm 2{ }^{\circ} \mathrm{C}$ until 180 days of curing. Uniaxial compressive strength according to EN 12390-3 [51] and modulus of elasticity according to EN 12390-13 [52] were also determined.

\subsubsection{Resonant Fatigue Test}

Resonant fatigue is a technique that allows fatigue testing at the resonant frequency of the system. This resonant frequency depends on the stiffness of the system, and, in the 
case of concrete, the stiffness is highly dependent on both the load values between which it is being calculated and the degree of cracking of the specimens.

The concrete's compressive resonant fatigue behaviour was studied using the Locati method, which enabled the estimation of the fatigue limit using a single specimen. For this purpose, the minimum stress value $\left(\sigma_{0}\right)$, corresponding to the lower limit, was fixed, and the upper limit of the maximum stress range $\left(\sigma_{j}\right)$ was varied in steps, where $j$ represents the different steps. Six loading steps with $1 \times 10^{5}$ cycles each were established, and a sinusoidal wave was applied at resonance by means of load control.

The specimens were instrumented with two $60 \mathrm{~mm}$ strain gauges to measure the strains. These were placed diametrically opposite to the central axis of the specimen and centred in height, and bonded with two-component epoxy resin. The strains recorded in both gauges were averaged for the calculations.

The test programme for the determination of the resonant fatigue limits is shown in detail in Table 5. Based on the uniaxial compressive strengths $\left(f_{c d, 180}\right)$ of the set of specimens, the minimum stress, $\sigma_{\min }$, was defined as $2.5 \mathrm{MPa}$ and the maximum initial stress, $\sigma_{\max }$, as $12.5 \mathrm{MPa}$, and an increase, $\Delta$, in the maximum stresses of $5.0 \mathrm{MPa}$ was considered in each successive step.

Table 5. Fatigue test parameters by the Locati method.

\begin{tabular}{ccccccc}
\hline $\begin{array}{c}\text { Step } \\
j\end{array}$ & $\begin{array}{c}\text { Cycle } \\
\boldsymbol{N}\end{array}$ & $\begin{array}{c}\sigma_{\min }-\sigma_{\mathbf{0}} \\
{[\mathbf{M P a}]}\end{array}$ & $\begin{array}{c}\sigma_{\max }-\sigma_{j} \\
{[\mathrm{MPa}]}\end{array}$ & $\begin{array}{c}\Delta \\
{[\mathbf{M P a}]}\end{array}$ & $\begin{array}{c}\sigma_{\text {med }} \\
{[\mathbf{M P a}]}\end{array}$ & $\begin{array}{c}\text { Amplitude } \\
{[\mathrm{MPa}]}\end{array}$ \\
\hline 1 & $0-1 \times 10^{5}$ & 2.5 & 12.5 & 5.0 & 7.5 & 5.0 \\
2 & $1 \times 10^{5}-2 \times 10^{5}$ & 2.5 & 17.5 & 5.0 & 10.0 & 7.5 \\
3 & $2 \times 10^{5}-3 \times 10^{5}$ & 2.5 & 22.5 & 5.0 & 12.5 & 10.0 \\
4 & $3 \times 10^{5}-4 \times 10^{5}$ & 2.5 & 27.5 & 5.0 & 15.0 & 12.5 \\
5 & $4 \times 10^{5}-5 \times 10^{5}$ & 2.5 & 32.5 & 5.0 & 17.5 & 15.0 \\
6 & $5 \times 10^{5}-6 \times 10^{5}$ & 2.5 & 37.5 & 5.0 & 20.0 & 17.5 \\
\hline
\end{tabular}

The fatigue limit was established from Equation (1), which was determined by correlating tests on different types of concrete by applying the Locati and Staircase methods [53].

$$
L_{F}=0.8 * \Delta \sigma_{L}
$$

where $L_{F}$ is the fatigue limit (MPa) and $\Delta \sigma_{L}$ is the stress range of the Locati test rupture step $(\mathrm{MPa})$.

In addition, the influence coefficient (IC) was defined as the ratio of the fatigue limit to the compressive strength in percent.

The resonance frequency tests were carried out with the Zwick/Roell Amsler 400 HFP 5100 Vibrophores (Figure 2), which have a maximum load capacity of $400 \mathrm{kN}$, maximum mean load of $\pm 300 \mathrm{kN}$, maximum force amplitude of $\pm 200 \mathrm{kN}$, and a test frequency range between $35 \mathrm{~Hz}$ and $300 \mathrm{~Hz}$. 


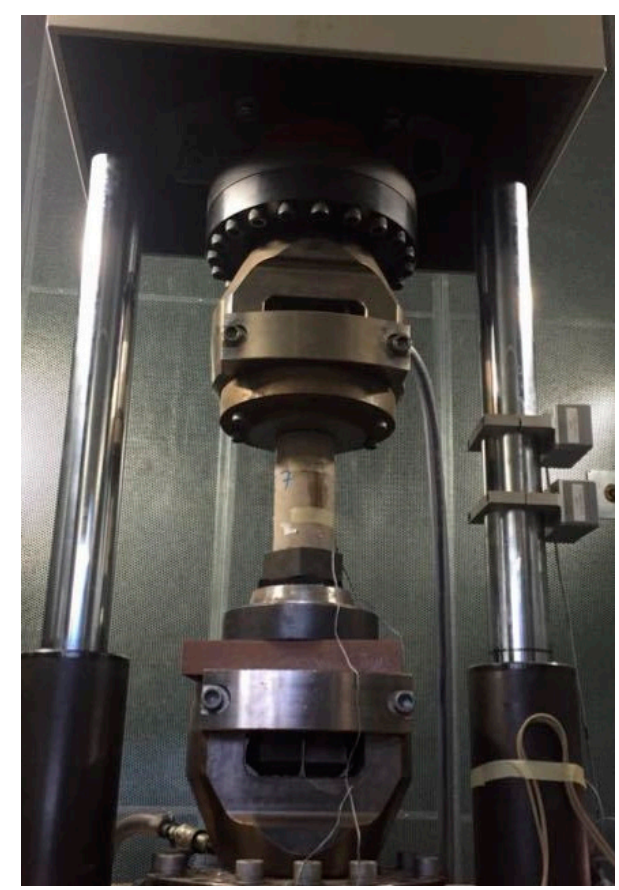

Figure 2. Zwick Amsler 400 HFP 5100 Vibrophore equipment. Schematic diagram of equipment and test specimen.

\subsubsection{Post-Processing Experimental Results}

During the fatigue tests, a data acquisition system was programmed to periodically record blocks of 0.03 seconds' duration of the force applied by the resonance machine and the strain recorded by each of the two strain gauges attached to the specimens. In this work, post-processing tasks were carried out to facilitate the interpretation of the results obtained. Specifically, a one degree Fourier regression [54-56] was performed to enable the fitting of the data to a harmonic function (2) [56]:

$$
y(t)=a_{0}+a_{1} * \cos (w * t)+b_{1} * \sin (w * t)
$$

where $a_{0}, a_{1}$ and $b_{1}$ are regression parameters and $w$ is the angular frequency. This equation can be transformed into a typical sinusoidal Equation (3) by using the following relationships (4) [56]:

$$
\begin{gathered}
y(t)=y_{0}+A * \sin \left(w * t+\varphi_{0}\right) \\
y_{0}=a_{0} ; \quad A=\sqrt{a_{1}^{2}+b_{1}^{2}} ; \quad \varphi_{0}=\frac{\pi}{2}-\arctan \left(\frac{b_{1}}{a_{1}}\right)
\end{gathered}
$$

where $y_{0}$ is the vertical offset, $A$ is the amplitude and $\varphi_{0}$ is the phase shift of the sinusoidal wave. Moreover, the angular frequency and the testing frequency are related by the following Equation (5) [56]:

$$
w=2 * f * \pi * \varphi_{0}
$$

Figure 3 shows an example comparing the results acquired by raw data (discrete points) and the regression obtained (continuous function). 

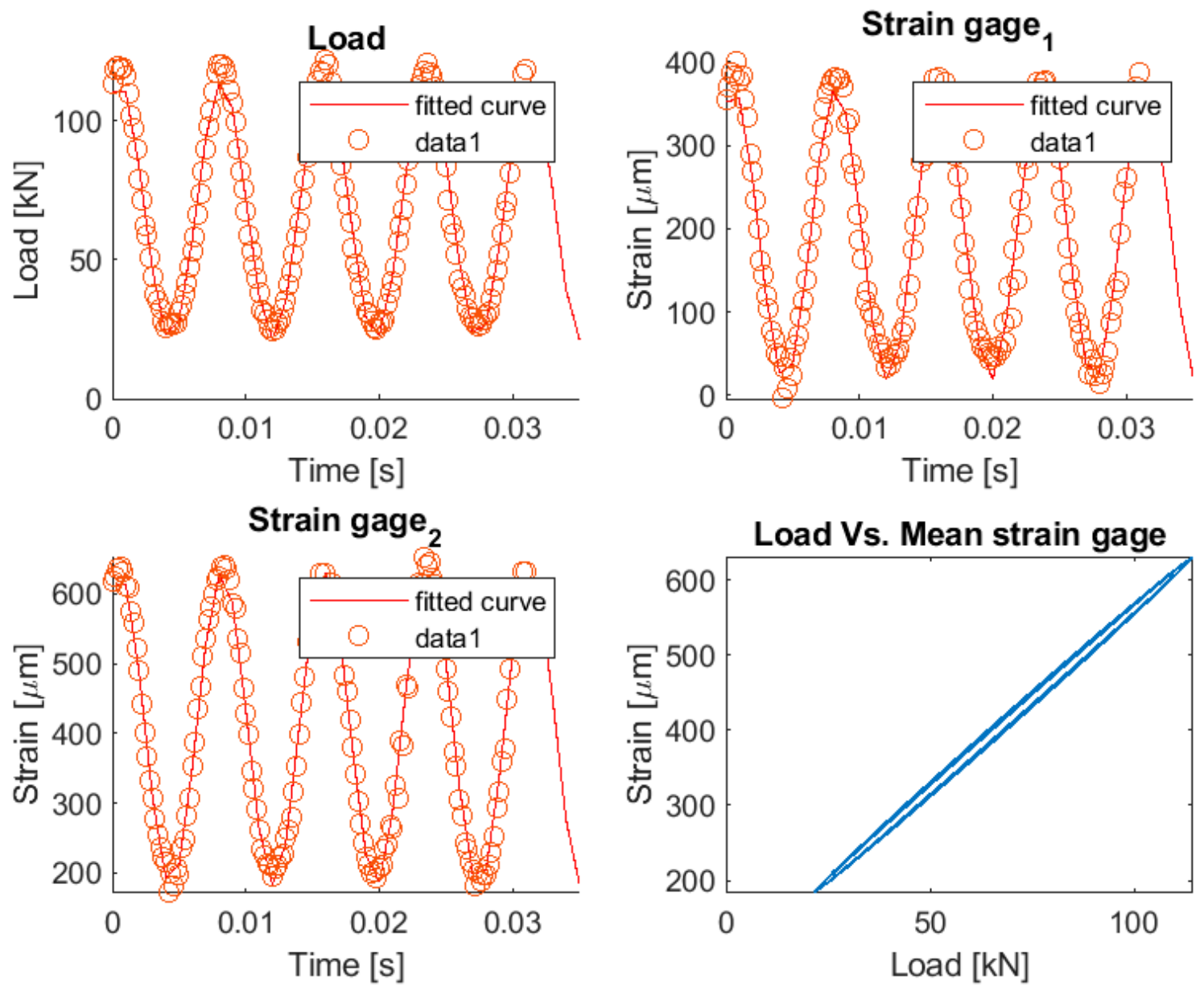

Figure 3. Example of the correlation between the recorded data and fitting values.

\subsubsection{Mix Design}

Batching for all the concrete mixes is given in Table 6. All mixes, irrespective of the MRA and/or NA content, were designed with the British mix approach [57], using the following starting conditions: (i) concrete compressive strength at 28 days, in $150 \mathrm{~mm}$ diameter and $300 \mathrm{~mm}$ height specimens, $f_{c k}=30 \mathrm{MPa}$; (ii) cement strength class, $42.5 \mathrm{R}$; (iii) effective $\mathrm{w} / \mathrm{c}$ ratio: 0.45 ; and (iv) aggregate with a maximum size of $20 \mathrm{~mm}$. The natural moisture content of all aggregates at the time of manufacture of the mixes and the water absorption were also considered. The concretes were prepared in the laboratory as follows: coarse and fine aggregates were mixed for $30 \mathrm{~s}$, then cement was added and mixed for $60 \mathrm{~s}$ to homogenise the mixture. The additive was dissolved in $10 \%$ of the total water content and mixed with the solids for $45 \mathrm{~s}$. With the mixer running, $70 \%$ of the total volume of water was added and mixed for $120 \mathrm{~s}$, after which the remaining $20 \%$ of the water was added and mixed for $240 \mathrm{~s}$. The mixer was then switched off, the fresh properties were determined and the mixture was poured into the respective moulds, according to the European standard (EN 12390-1) [50]. Figure 4 shows the modulus of elasticity of the different mixes [16]. 
Table 6. Concrete mix proportions.

\begin{tabular}{|c|c|c|c|c|c|c|}
\hline \multirow{2}{*}{$\begin{array}{c}\text { Material } \\
{\left[\mathrm{kg} / \mathrm{m}^{3}\right]}\end{array}$} & \multicolumn{6}{|c|}{ Type } \\
\hline & HP & HR-25 & HR-50 & HP-R & HRR-25 & HRR-50 \\
\hline NA-S & 732.36 & 720.79 & 705.38 & 732.36 & 720.79 & 705.38 \\
\hline NA-M & 382.96 & 282.69 & 184.43 & 382.96 & 282.69 & 184.43 \\
\hline NA-G & 766.69 & 565.94 & 369.22 & 766.69 & 565.94 & 369.22 \\
\hline MRA-M & - & 90.75 & 177.62 & - & 90.75 & 177.62 \\
\hline MRA-G & - & 182.80 & 357.77 & - & 182.80 & 357.77 \\
\hline OPC & 400 & 400 & 400 & - & - & - \\
\hline OPC-25CDW & - & - & - & 400 & 400 & 400 \\
\hline $\mathrm{W}$ & 193.03 & 202.08 & 210.63 & 193.03 & 202.08 & 210.63 \\
\hline SP & 6.20 & 6.20 & 6.20 & 6.20 & 6.20 & 6.20 \\
\hline$(\mathrm{w} / \mathrm{c})$ effective & 0.48 & 0.50 & 0.53 & 0.48 & 0.50 & 0.53 \\
\hline \multicolumn{7}{|c|}{ Physical and mechanical properties } \\
\hline$\rho\left(\mathrm{kg} / \mathrm{m}^{3}\right)$ & 2340 & 2310 & 2290 & 2350 & 2310 & 2240 \\
\hline$f_{c d, 180}(\mathrm{MPa})$ & 53.5 & 47.0 & 48.8 & 50.2 & 47.5 & 47.5 \\
\hline
\end{tabular}

Note: $\rho$, hardened density and $f_{c m}$, compressive strength.

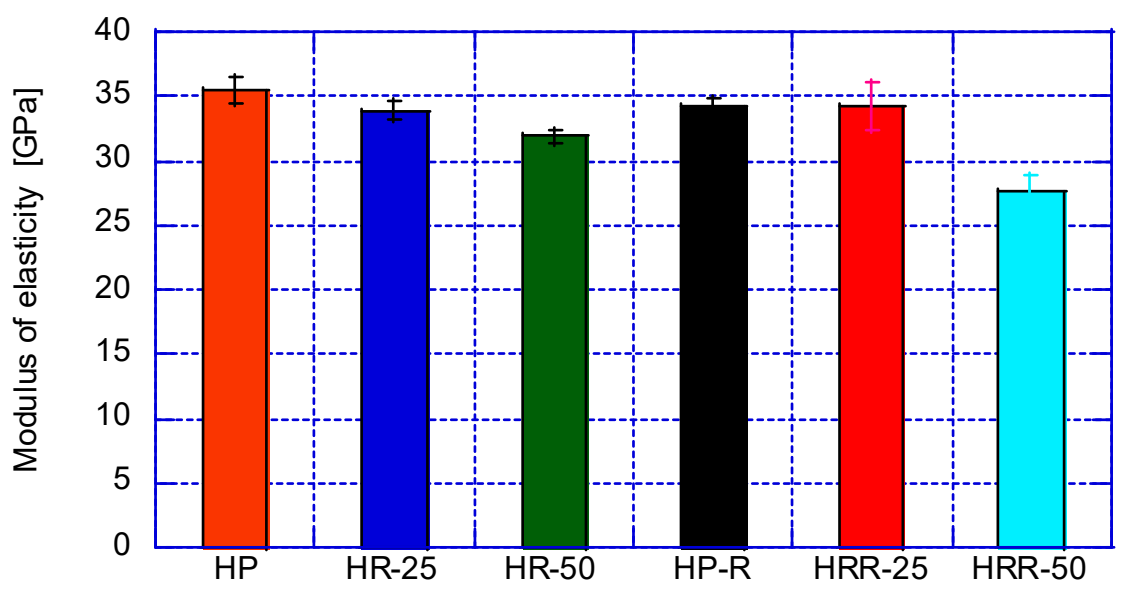

Figure 4. Modulus of elasticity of the different mixes.

\section{Results and Discussion}

\subsection{Fatigue Limit}

Table 7 shows the values obtained from the Locati resonant fatigue tests for all mixes. In addition, to complement this parameter, the values of $f_{c d, 180}$ (Table 6) and IC were added, which enabled the evaluation of the effect of fatigue on each type of concrete.

Table 7. Fatigue limit obtained from Locati Method.

\begin{tabular}{ccccc}
\hline Material & $f_{c \boldsymbol{c}, \mathbf{1 8 0}}[\mathbf{M P a}]$ & $\boldsymbol{\Delta} \sigma_{\boldsymbol{L}}[\mathrm{MPa}]$ & $\boldsymbol{L}_{\boldsymbol{F}}[\mathbf{M P a}]$ & $\boldsymbol{I C}[\boldsymbol{\%}]$ \\
\hline HP & 53.5 & 27.5 & 22.0 & 41.12 \\
HR25 & 47.0 & 18.4 & 14.8 & 31.49 \\
HR50 & 48.8 & 27.5 & 22.0 & 45.08 \\
HRR & 50.2 & 25.3 & 20.3 & 40.44 \\
HRR25 & 47.5 & 27.5 & 22.0 & 46.32 \\
HRR50 & 47.5 & 20.6 & 16.5 & 34.74
\end{tabular}

Note: $f_{c d, 180}$ : uniaxial compressive strength at 180 days; $\Delta \sigma_{L}$ : stress range of the Locati test rupture step; $L_{F}:$ fatigue limit; IC: Influence coefficient $\left(L_{f} / f_{c d, 180} 100\right)$.

In all cases, fatigue reduced the strength of the specimens to between 30 and $45 \%$ of the $f_{c d, 180}$. Regarding the effect of the presence of both MRA and OPC-25CDW on the IC, there seemed to be no clear effect. This can be explained mainly by the high dispersion 
associated with fatigue failure, as this parameter is highly influenced by local phenomena. Furthermore, analysing the strength properties of concrete [15], neither the presence of MRA nor OPC-25CDW produced a significant change in the strength of the material. The little influence of MRA and OPC-25CDW on the IC is because, as pointed out by Lantsoght et al. [58], the fatigue strength of a recycled concrete does not depend only on the presence of RA, but also depends to a large extent on water/cement ratio, cement content, concrete type, rest periods, curing conditions and age during loading, and in this case, it was concrete with a high cement content per cubic metre and with high-quality MRA [16]. Furthermore, because the method used for the determination of the fatigue limit was based on a test that applies load steps, the resolution of this method will be similar to the size of the steps used. Therefore, if the differences between mixtures were smaller than the step size, they will be masked by the resolution of the test.

\subsection{Strain Evolution Test}

Figures 5 and 6 show the evolution of the strain amplitude of the two series of six mixes analysed during the accelerated fatigue test. Figure 4 shows the results corresponding to the OPC mix, and Figure 5 shows the results corresponding to the OPC-25CDW mix.

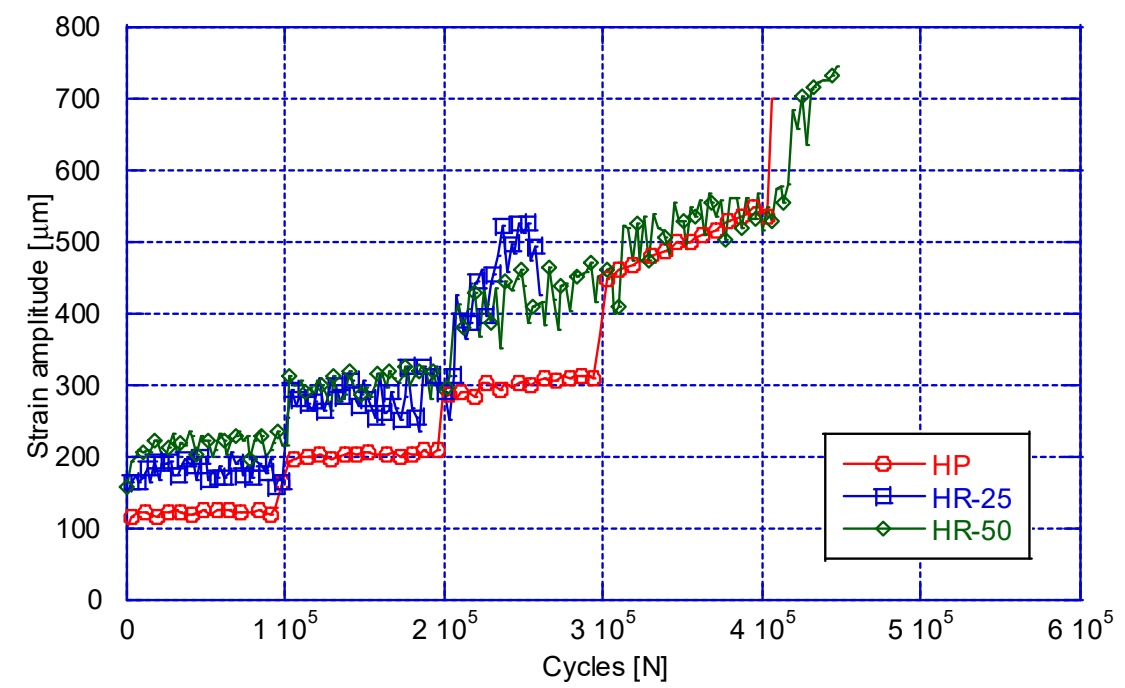

Figure 5. Strain amplitude evolution during a Locati test on the OPC mixes.

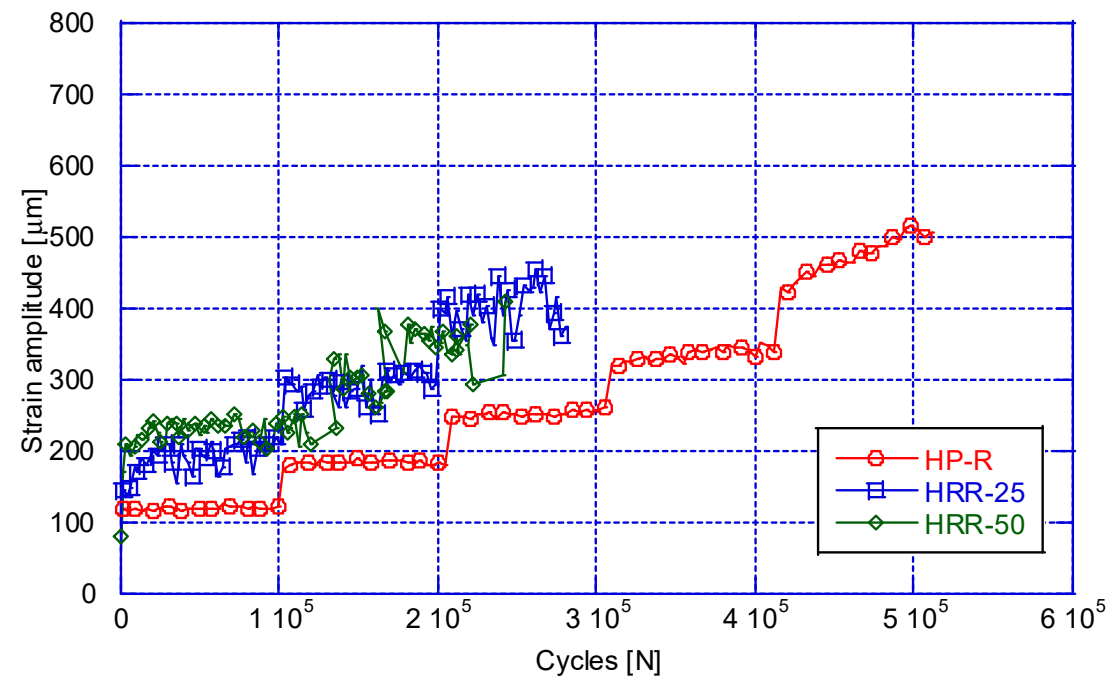

Figure 6. Strain amplitude evolution during a Locati test on the OPC-25CDW mixes. 
It can be observed that the presence of MRA increased the strain amplitude recorded for both OPC and OPC-25CDW concretes. This increase in the strain of the concrete with MRA could also be observed in the static tests if we compared the elastic modulus of the different mixes. These results are in agreement with those observed by other authors who have performed fatigue tests on RA concrete analysing the strain evolution [23-26,29,31]. On the other hand, the influence of the type of cement on the strain of the specimens during the fatigue tests was much lower; this effect is also in agreement with the static values obtained in the elastic modulus tests [16]. From Figures 4 and 5, it can also be seen that the presence of MRA resulted in less homogeneous results, which is in agreement with other research $[17,59]$.

In view of the results, which showed both equivalent compressive strength and fatigue strength for both conventional and recycled concretes, it could be considered to use these concretes for the main applications that are susceptible to fatigue damage, such as the railway superstructure, sleepers, or tracks, bridges both for railroad and for road traffic, offshore structures subjected to wind and sea waves and/or wind power tower. Nevertheless, it should be noted that lower modulus results were obtained, which should be taken into account, especially in applications where the concrete is prestressed.

\subsection{Frequency Evolution}

Figure 7 shows an example of the evolution of the resonant frequency of the set during the fatigue test as a function of the number of cycles. The fatigue testing machine used is characterised by always testing at the resonance frequency of the test machine and specimen assembly, which depends mainly on the stiffness of the assembly; the stiffer it is, the higher the resonance frequency. As shown in this figure, the resonance frequency was not constant throughout the test, which implied that the specimen underwent a series of changes in its mechanical properties during the test. First, it can be seen that when each time a step change occurred, there was also an increase in the resonance frequency. This is because a step-change implies an increase in the stress range applied to the specimen, which generally results in a higher stiffness. Second, it can be seen that, after the first few cycles, there was a reduction in the resonance frequency, corresponding to a stabilisation phase. In the fourth step, this effect was not seen because it is a phenomenon of short duration, which only affects a few cycles, and the data acquisition did not record any of them. However, it is a phenomenon observed by other authors [29,31]. In the first step, it can be seen that, once this first phase was overcome, the resonance frequency remained constant, which means that the specimen was in a stationary state, i.e., the specimen was suffering little damage, and, therefore, it could withstand a large number of cycles without breaking. It was only in the last step that the resonance frequency decreased. This drop in frequency was the consequence of an increase in the specimen deformation, which can be explained by the growth of micro-cracks in the concrete specimen that will lead to specimen failure [60]. For this reason, observing that the resonance frequency decreased (after the initial stabilisation phase) is considered as an indicator of being close to failure of the specimen and that the endurance of the material has been exceeded. Finally, this methodology may be a new way to measure the fatigue limit through resonance frequency monitoring. 


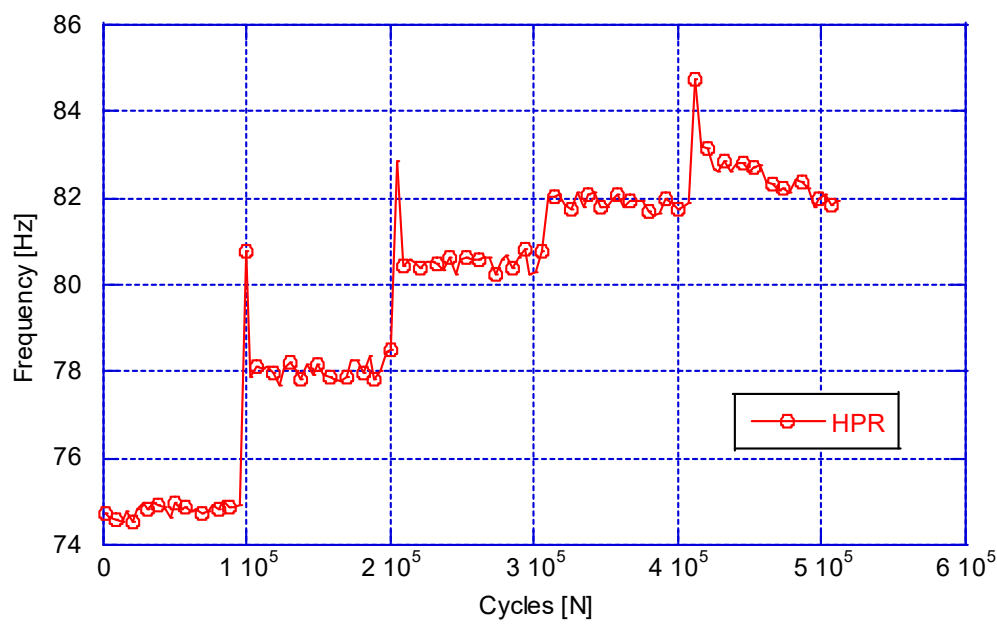

Figure 7. Resonance fatigue frequency evolution during a Locati test.

Figures 8 and 9 show an example of the comparison between the test frequencies obtained for each type of concrete as a function of the percentage of NA replaced by MRA for each type of cement.

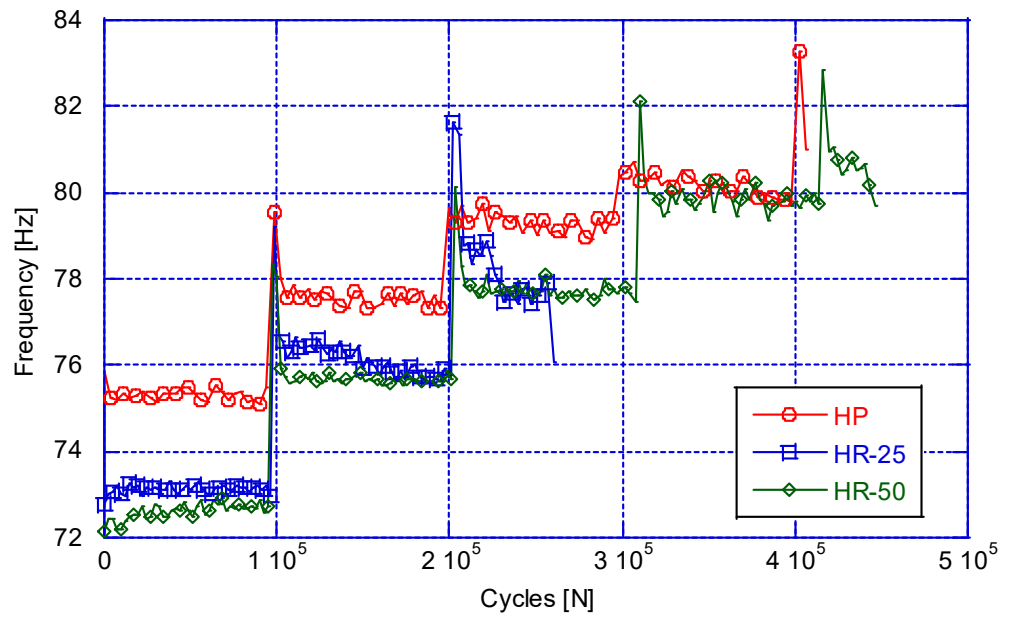

Figure 8. Resonance fatigue frequency evolution during a Locati test for OPC mixes.

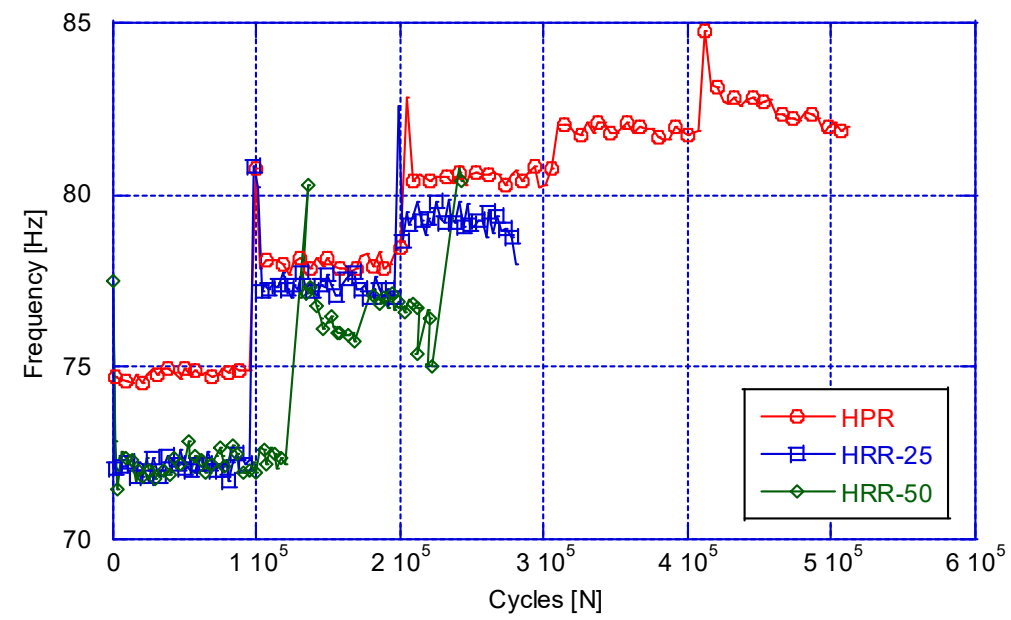

Figure 9. Resonance fatigue frequency evolution during a Locati test for OPC-25CDW mixes.

Figure 7 shows the results for the OPC concretes. It can be seen that the behavioural phases described above were satisfied. As the percentage of replacement increased, the 
resonance frequency decreased, decreasing the stiffness of the specimen, which was in agreement with the results obtained from the elastic modulus tests and with the strain values previously shown. Figure 8 shows the results of the mixes with OPC-25CDW. As in the case of Figure 7, the phases described above can be seen. In these mixes, it was also observed that in those concretes with MRA, the resonance frequencies were lower than in the case of concretes without MRA. Likewise, these values agreed with the results obtained in the elastic modulus and strain tests.

\subsection{Correlation between Strain and Frequency during a Resonance Fatigue Test}

In the two previous sections, the evolution of the strain amplitude and the resonance frequency was shown, and it was commented that there is a relationship between the two parameters. Figure 10 shows an example of a comparison between the two parameters for the same test.

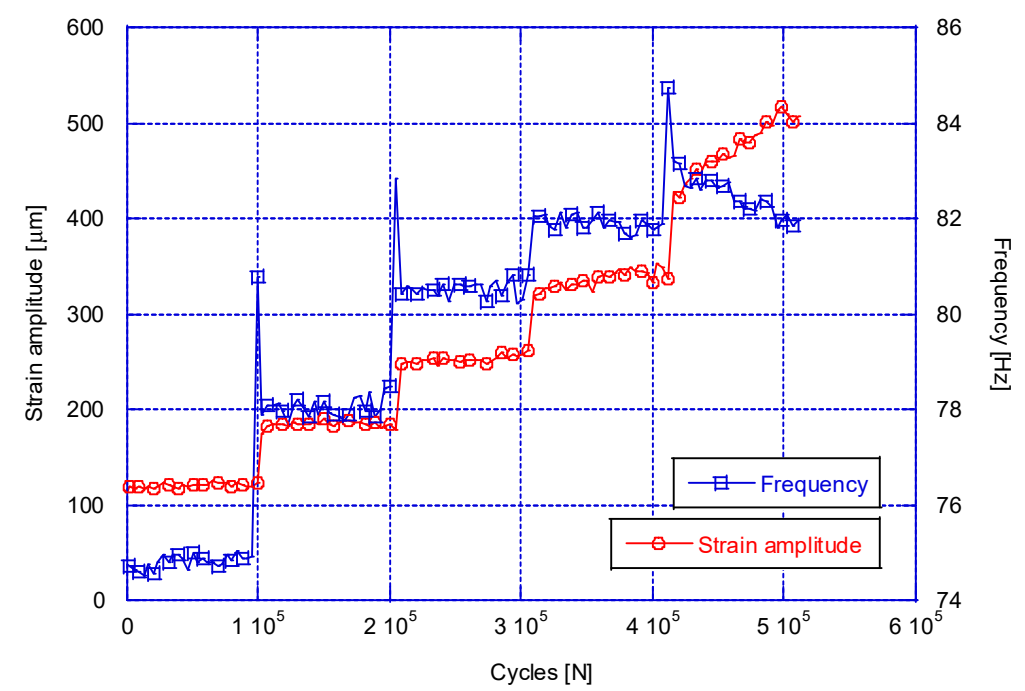

Figure 10. Comparison of the strain amplitude and the resonance frequency during a Locati fatigue test.

Figure 10 show that both parameters suffer abrupt changes at the beginning of each step. In phases where one parameter remained constant, the other also remained constant, although the frequency values seemed to be more stable than the strain values. In phases where changes occurred within the same step, i.e., where the loads remained constant, the effect of the deterioration of the specimens was the inverse for each of these parameters, the frequency decreased and strain increased. At step changes, both parameters underwent punctual increases, while within each step, the change undergone by each parameter was the inverse; this was due to the modifications of the applied stress values. As the applied load amplitude increased, the specimen strained more, and the ratio between force and strain (stiffness) also increased at each step. However, within the same step, as the displacement amplitude increased, the stiffness decreased.

To analyse the ratio between load and strain, Figure 11 shows an example of the evolution of a parameter correlated with stiffness, namely the elastic modulus, during a fatigue test. 


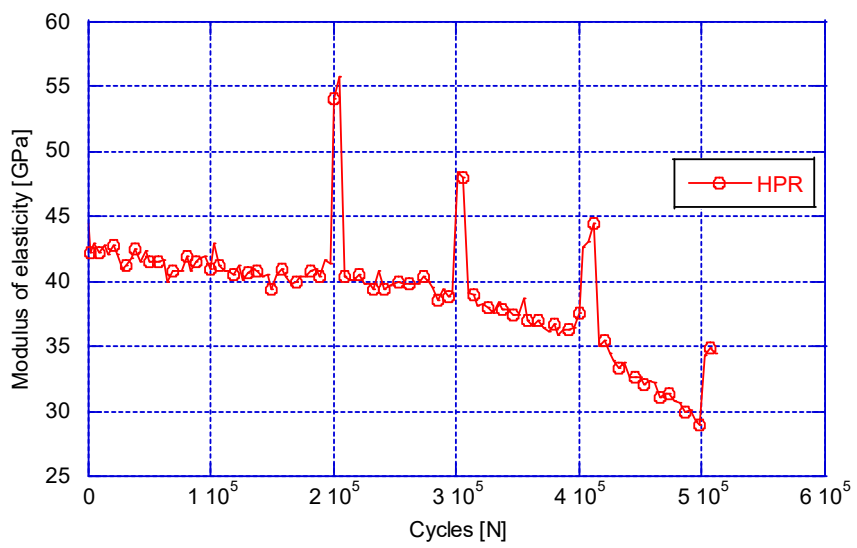

Figure 11. Modulus of elasticity evolution during a Locati test.

Figure 11 shows how, contrary to strain amplitude or resonance frequency, the elastic modulus was a parameter that had a continuous behaviour, if we do not take into account the stabilisation period at the beginning of a step. Moreover, it is a parameter that always decreased [23-25,61]. This is because as the specimen is damaged, the micro-cracks present in the concrete grow, which results in a lower elastic modulus.

\subsection{Morphological Analysis of Fractures}

Figure 12 shows examples of the failure surfaces of the six types of concretes evaluated in this work. On the left the series of mixes with OPC. On the right, the series of mixes with OPC-25CDW.
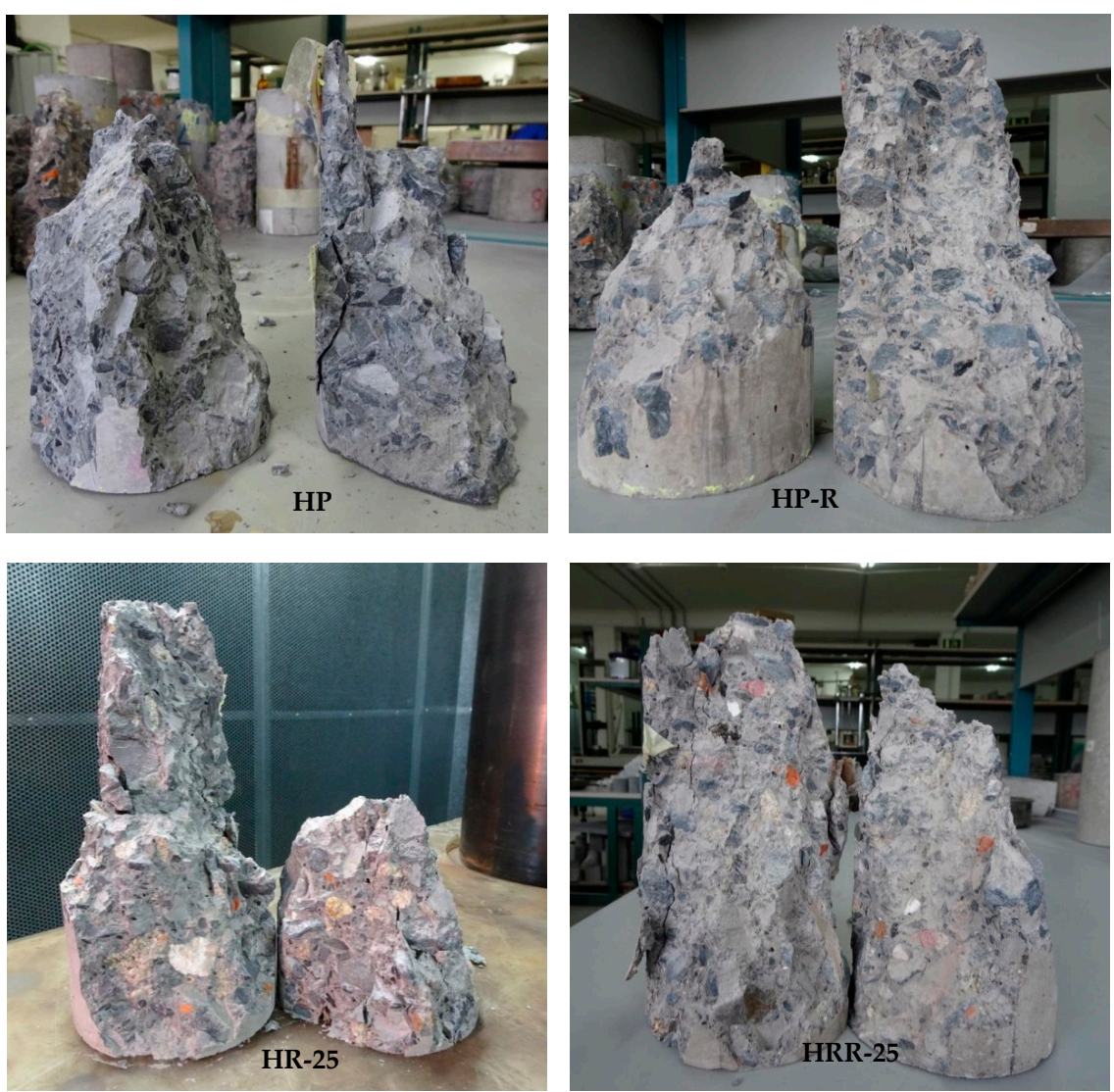

Figure 12. Cont. 

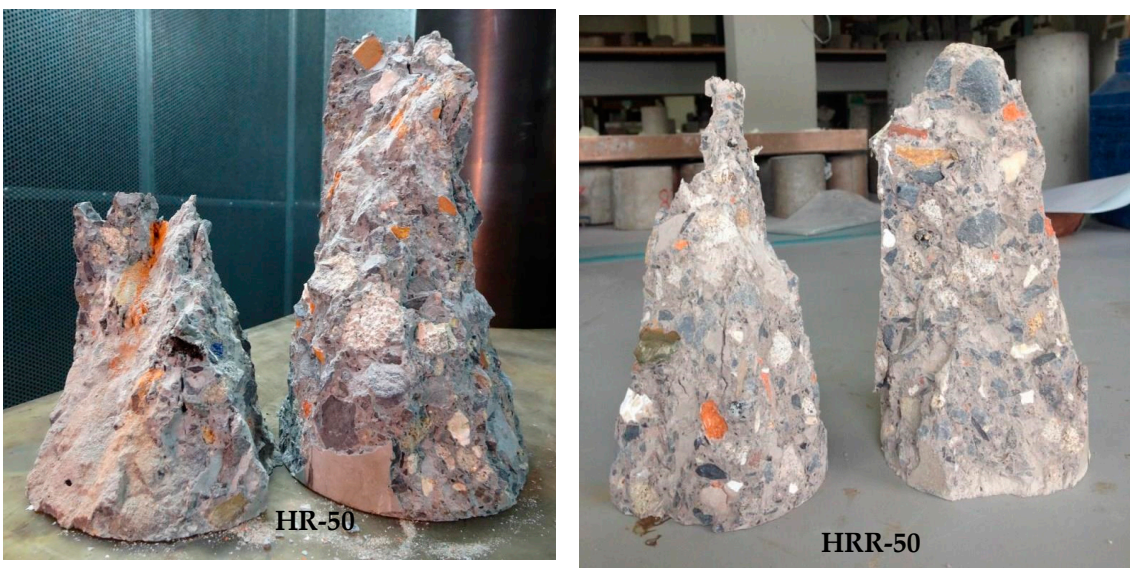

Figure 12. Fracture surface of samples broken during fatigue tests.

Comparing the failure surfaces of those concretes with different degrees of replacement of NA by MRA, different failure mechanisms were observed, similar to those observed by other authors who also performed fatigue tests on concrete [26,61]. In Figure 12, the following patterns were observed on the fracture surfaces of specimens incorporating NA: paste planes were seen, which before fatigue were in contact with aggregates; cracks were seen at the edges of some aggregates; pieces of aggregate were seen protruding above the fracture surface.

Figure $13 b$ shows a detail of the fracture surface of a specimen with MRA. In this figure, the following patterns can be seen: (i) in the case of aggregates from structural concrete, it can be seen that the fracture surface had generated a plane through the aggregate and (ii) in the case of an aggregate of ceramic origin, it can be seen that this aggregate had been pulverized.

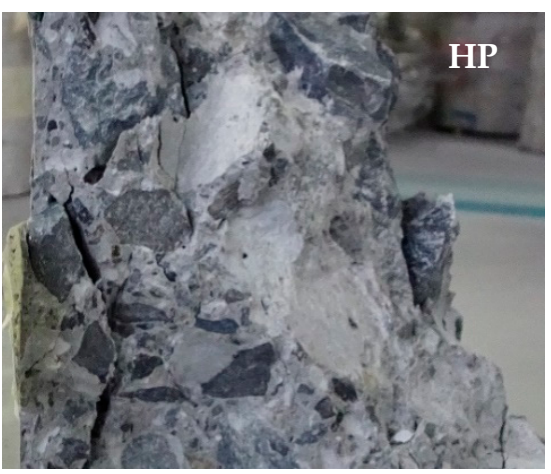

(a)

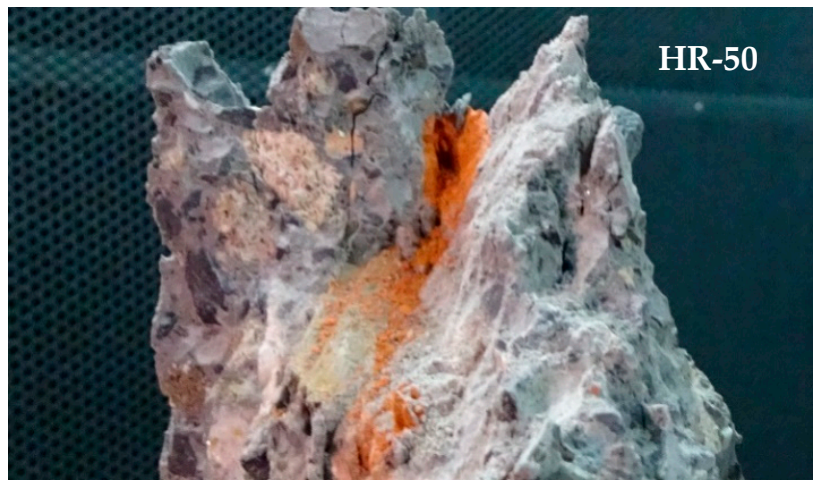

(b)

Figure 13. Fracture surface detail of samples broken during fatigue tests: HP sample (a) and HR-50 sample (b).

Several authors have concluded that the cracking of the specimens occurs because the cracks propagate through the weaker planes [62-65]. Based on the previously mentioned observations, it is possible to ensure that in those concretes with $0 \%$ replacement, and the cracks occur through the paste-aggregate interface (ITZ), i.e., the weakest zone of the specimens is the paste-aggregate interface. It can also be seen that the presence of MRA, especially in those of ceramic origin, can cause the rupture not to occur through the ITZ, because the aggregates have lower mechanical properties so that cracks can advance through them.

On the fracture surface of the fatigue-tested specimens, no different fracture mechanisms were observed in relation to the use of different binders, OPC-25CDW or OPC. It can be observed that the paste had a different colour. It should be noted that, based on the colour of the paste of the concrete with OPC-25CDW, it was possible to estimate that 
the specimen was "very dry", which is in agreement with what was observed once the test was completed, where the specimens were at a high temperature. This temperature increase has also been detected in other resonant fatigue studies on concrete [29].

\section{Conclusions}

The main conclusions derived from this research are:

- In the mixtures studied, the resonant fatigue limit was between 30 and $45 \%$ of the compressive strength.

- The fatigue results had a large scatter, and no direct influence on the resonant compressive fatigue limit was observed due to the presence of mix recycled aggregate.

- The presence of mixed recycled aggregates in the concretes increased the strain recorded during the resonance compressive fatigue tests. The presence of recycled cement did not affect the strain values.

- $\quad$ The resonance frequencies were lower in the concretes with MRA because the stiffness of the system provided by the presence of MRA increased the strain suffered by the specimen.

- For all cases, it was observed that during resonance fatigue tests with constant load cycles, as the strain increased, the resonance frequency decreased.

- In the compressive resonance fatigue tests, the unmixed MRA specimens exhibited fracture planes across the paste-aggregate interface. While the specimens with MRA showed cracks through the recycled concrete aggregates and pulverisation of the ceramic fractions.

- The strength of all the concretes was similar. The presence of mixed recycled aggregates had a greater effect on the dynamic response (increased strain and decreased resonance frequency) than the presence of recycled cement, which did not show any influence on the dynamic response.

- The characterisation in resonant fatigue allowed a reduction in test durations and the comparison of the fatigue life of different types of recycled concrete, even with recycled cement. However, the dispersion obtained in the results suggests that the more heterogeneous concretes are more sensitive to resonant fatigue. For this reason, for recycled concretes, the method does not seem directly comparable with the classical methods of static characterisation.

Author Contributions: A.Y. and B.C. performed the experiments; J.S.-A., A.Y. and B.C. analysed the data and wrote the paper; C.T. and C.M. supervised the research work and revised the paper. All the authors contributed to the experiment design and analysed and discussed the findings. All authors have read and agreed to the published version of the manuscript.

Funding: This research was funded by the Spanish Ministry of Science and Innovation within the framework of the project BIA 2013-48876-C3-2-R.

Institutional Review Board Statement: Not applicable.

Informed Consent Statement: Not applicable.

Data Availability Statement: Data sharing not applicable.

Acknowledgments: The first author benefited from the Ministry of Education, Culture and Sport's pre-doctoral grant FPU16/02693. The authors would like to acknowledge the "Augusto Gonzalez Linares" postdoctoral grant program of the University of Cantabria for support.

Conflicts of Interest: The authors have no conflict of interest that may have influenced the research described in this paper.

\section{References}

1. Monteiro, P.J.M.; Miller, S.A.; Horvath, A. Towards Sustainable Concrete. Nat. Mater. 2017, 16, 698-699. [CrossRef]

2. Li, J.; Zhang, W.; Li, C.; Monteiro, P.J.M. Green Concrete Containing Diatomaceous Earth and Limestone: Workability, Mechanical Properties, and Life-Cycle Assessment. J. Clean. Prod. 2019, 223, 662-679. [CrossRef] 
3. Miller, S.A.; Horvath, A.; Monteiro, P.J.M. Impacts of Booming Concrete Production on Water Resources Worldwide. Nat. Sustain. 2018, 1, 69-76. [CrossRef]

4. Miller, S.A. Supplementary Cementitious Materials to Mitigate Greenhouse Gas Emissions from Concrete: Can There Be Too Much of a Good Thing? J. Clean. Prod. 2018, 178, 587-598. [CrossRef]

5. European Commission. Towards a Circular Economy: A Zero Waste Programme for Europe; European Commission: Brussels, Belgium, 2019.

6. Cantero, B.; Sáez del Bosque, I.F.; Matías, A.; Medina, C. Statistically Significant Effects of Mixed Recycled Aggregate on the Physical-Mechanical Properties of Structural Concretes. Constr. Build. Mater. 2018, 185, 93-101. [CrossRef]

7. Bravo, M.; de Brito, J.; Pontes, J.; Evangelista, L. Mechanical Performance of Concrete Made with Aggregates from Construction and Demolition Waste Recycling Plants. J. Clean. Prod. 2015, 99, 59-74. [CrossRef]

8. Medina, C.; Zhu, W.; Howind, T.; Frías, M.; Sánchez de Rojas, M.I. Effect of the Constituents (Asphalt, Clay Materials, Floating Particles and Fines) of Construction and Demolition Waste on the Properties of Recycled Concretes. Constr. Build. Mater. 2015, 79, 22-33. [CrossRef]

9. Thomas, C.; Setién, J.; Polanco, J.A.; Alaejos, P.; Sánchez de Juan, M. Durability of Recycled Aggregate Concrete. Constr. Build. Mater. 2013, 40, 1054-1065. [CrossRef]

10. Cantero, B.; del Bosque, I.F.S.; Matías, A.; de Rojas, M.I.S.; Medina, C. Water Transport Mechanisms in Concretes Bearing Mixed Recycled Aggregates. Cem. Concr. Compos. 2020, 107, 103486. [CrossRef]

11. Debieb, F.; Courard, L.; Kenai, S.; Degeimbre, R. Mechanical and Durability Properties of Concrete Using Contaminated Recycled Aggregates. Cem. Concr. Compos. 2010, 32, 421-426. [CrossRef]

12. Guo, H.; Shi, C.; Guan, X.; Zhu, J.; Ding, Y.; Ling, T.-C.; Zhang, H.; Wang, Y. Durability of Recycled Aggregate Concrete-A Review. Cem. Concr. Compos. 2018, 89, 251-259. [CrossRef]

13. Majhi, R.K.; Nayak, A.N.; Mukharjee, B.B. Development of Sustainable Concrete Using Recycled Coarse Aggregate and Ground Granulated Blast Furnace Slag. Constr. Build. Mater. 2018, 159, 417-430. [CrossRef]

14. Çakır, Ö. Experimental Analysis of Properties of Recycled Coarse Aggregate (RCA) Concrete with Mineral Additives. Constr. Build. Mater. 2014, 68, 17-25. [CrossRef]

15. Cantero, B.; Sáez del Bosque, I.F.; Matías, A.; Sánchez de Rojas, M.I.; Medina, C. Inclusion of Construction and Demolition Waste as a Coarse Aggregate and a Cement Addition in Structural Concrete Design. Arch. Civ. Mech. Eng. 2019, 19, 1338-1352. [CrossRef]

16. Thomas, C.; Cimentada, A.I.; Cantero, B.; Sáez del Bosque, I.F.; Polanco, J.A. Industrial Low-Clinker Precast Elements Using Recycled Aggregates. Appl. Sci. 2020, 10, 6655. [CrossRef]

17. Cantero, B.; Bravo, M.; de Brito, J.; Sáez del Bosque, I.F.; Medina, C. Mechanical Behaviour of Structural Concrete with Ground Recycled Concrete Cement and Mixed Recycled Aggregate. J. Clean. Prod. 2020, 275, 122913. [CrossRef]

18. Duan, Z.; Singh, A.; Xiao, J.; Hou, S. Combined Use of Recycled Powder and Recycled Coarse Aggregate Derived from Construction and Demolition Waste in Self-Compacting Concrete. Constr. Build. Mater. 2020, 254, 119323. [CrossRef]

19. Beltran, M.G.; Agrela, F.; Barbudo, A.; Ayuso, J.; Ramirez, A. Mechanical and Durability Properties of Concretes Manufactured with Biomass Bottom Ash and Recycled Coarse Aggregates. Constr. Build. Mater. 2014, 72, 231-238. [CrossRef]

20. Agrela, F.; Beltran, M.G.; Cabrera, M.; López, M.; Rosales, J.; Ayuso, J. Properties of Recycled Concrete Manufacturing with All-in Recycled Aggregates and Processed Biomass Bottom Ash. Waste Biomass Valorization 2018, 9, 1247-1259. [CrossRef]

21. Breccolotti, M.; Bonfigli, M.F. Fatigue Behaviour and Damage Accumulation in RAC Subjected to Cyclic Compressive Loadings. Constr. Build. Mater. 2020, 259, 120408. [CrossRef]

22. Mínguez, J.; Gutiérrez, L.; González, D.C.; Vicente, M.A. Plain and Fiber-Reinforced Concrete Subjected to Cyclic Compressive Loading: Study of the Mechanical Response and Correlations with Microstructure Using CT Scanning. Appl. Sci. 2019, 9, 3030. [CrossRef]

23. Xiao, J.; Li, H.; Yang, Z. Fatigue Behavior of Recycled Aggregate Concrete under Compression and Bending Cyclic Loadings. Constr. Build. Mater. 2013, 38, 681-688. [CrossRef]

24. Calderón, L.S.; Bairán, J. Semi-automatic detection and measurement of cracks in concrete elements in digital photos using image processing. Hormig. Acero 2020, 71, 21-27. [CrossRef]

25. Thomas, C.; Setién, J.; Polanco, J.A.; Lombillo, I.; Cimentada, A. Fatigue Limit of Recycled Aggregate Concrete. Constr. Build. Mater. 2014, 52, 146-154. [CrossRef]

26. Thomas, C.; Sosa, I.; Setién, J.; Polanco, J.A.; Cimentada, A.I. Evaluation of the Fatigue Behavior of Recycled Aggregate Concrete. J. Clean. Prod. 2014, 65, 397-405. [CrossRef]

27. Thomas, C.; Setién, J.; Polanco, J.A.; de Brito, J.; Fiol, F. Micro- and Macro-Porosity of Dry- and Saturated-State Recycled Aggregate Concrete. J. Clean. Prod. 2019, 211, 932-940. [CrossRef]

28. Zhang, H.; Zhao, Y. Integrated Interface Parameters of Recycled Aggregate Concrete. Constr. Build. Mater. 2015, 101, 861-877. [CrossRef]

29. Sainz-aja, J.; Thomas, C.; Carrascal, I.; Polanco, J.A.; Brito, J. De Fast Fatigue Method for Self-Compacting Recycled Aggregate Concrete Characterization. J. Clean. Prod. 2020, 123263. [CrossRef]

30. Helland, S. Design for Service Life: Implementation of Fib Model Code 2010 Rules in the Operational Code ISO 16204. Struct. Concr. 2013, 14, 10-18. [CrossRef]

31. Sainz-Aja, J.; Thomas, C.; Polanco, J.A.; Carrascal, I. High-Frequency Fatigue Testing of Recycled Aggregate Concrete. Appl. Sci. 2019, 10, 10. [CrossRef] 
32. Martínez-Lage, I.; Martínez-Abella, F.; Vázquez-Herrero, C.; Pérez-Ordóñez., J.L. Properties of Plain Concrete Made with Mixed Recycled Coarse Aggregate. Constr. Build. Mater. 2012, 37, 171-176. [CrossRef]

33. Medina, C.; Zhu, W.; Howind, T.; Sánchez de Rojas, M.I.; Frías, M. Influence of Mixed Recycled Aggregate on the Physical-Mechanical Properties of Recycled Concrete. J. Clean. Prod. 2014, 68, 216-225. [CrossRef]

34. Mas, B.; Cladera, A.; del Olmo, T.; Pitarch, F. Influence of the Amount of Mixed Recycled Aggregates on the Properties of Concrete for Non-Structural Use. Constr. Build. Mater. 2012, 27, 612-622. [CrossRef]

35. Cantero, B.; Bravo, M.; de Brito, J.; Sáez del Bosque, I.F.; Medina, C. Water Transport and Shrinkage in Concrete Made with Ground Recycled Concrete-Additioned Cement and Mixed Recycled Aggregate. Cem. Concr. Compos. 2021, 103957. [CrossRef]

36. Alexandridou, C.; Angelopoulos, G.N.; Coutelieris, F.A. Mechanical and Durability Performance of Concrete Produced with Recycled Aggregates from Greek Construction and Demolition Waste Plants. J. Clean. Prod. 2018, 176, 745-757. [CrossRef]

37. Bravo, M.; de Brito, J.; Pontes, J.; Evangelista, L. Durability Performance of Concrete with Recycled Aggregates from Construction and Demolition Waste Plants. Constr. Build. Mater. 2015, 77, 357-369. [CrossRef]

38. European Comision. Construction and Demolition Waste Protocol; European Comision: Brussels, Belgium, 2016.

39. Tang, Q.; Ma, Z.; Wu, H.; Wang, W. The Utilization of Eco-Friendly Recycled Powder from Concrete and Brick Waste in New Concrete: A Critical Review. Cem. Concr. Compos. 2020, 114, 103807. [CrossRef]

40. Costa, C.; Marques, J.C. Feasibility of Eco-Friendly Binary and Ternary Blended Binders Made of Fly-Ash and Oil-Refinery Spent Catalyst in Ready-Mixed Concrete Production. Sustainability 2018, 10, 3136. [CrossRef]

41. European Committee for Standardization. EN 197. Cement. Part. 1: Composition, Specifications and Conformity Criteria for Common Cements; European Committee for Standardization: Brussels, Belgium, 2011.

42. Sánchez, M.I.; de Rojas, M.F.; Asensio, C.E. Medina Sanitary Ware Waste for Cements Manufacture, Obtention Proceeding and Cements That Are Included, PCT/ES2014/070406. 2014. Available online: https://patentscope2.wipo.int/search/en/detail.jsf? docId=WO2014188034 (accessed on 6 May 2021).

43. European Committee for Standardization. EN 933. Tests for Geometrical Properties of Aggregates_-Part. 11: Classification Test. for the Constituents of Coarse Recycled Aggregate; European Committee for Standardization: Brussels, Belgium, 2010.

44. Comisión Permanente del Hormigón Instrucción Hormigón Estructural. EHE-08 (Spanish Code on Structural Concrete). 2008 Available online: http:/ / asidac.es/asidac-en/wp-content/uploads/2016/07/EHE-ENG.pdf (accessed on 6 May 2021).

45. Agrela, F.; Sanchez de Juan, M.; Ayuso, J.; Geraldes, V.L.; Jimenez, J.R. Limiting Properties in the Characterisation of Mixed Recycled Aggregates for Use in the Manufacture of Concrete. Constr. Build. Mater. 2011, 25, 3950-3955. [CrossRef]

46. European Committee for Standardization. EN 12620. Aggregates for Concrete; European Committee for Standardization: Brussels, Belgium, 2013.

47. European Committee for Standardization. EN 1097. Tests for Mechanical and Physical Properties of Aggregates. Part. 6: Determination of Particle Density and Water Absorption; European Committee for Standardization: Brussels, Belgium, 2014.

48. European Committee for Standardization. EN 1097. Tests for Mechanical and Physical Properties of Aggregates. Part. 2: Methods for the Determination of Resistance to Fragmentation; European Committee for Standardization: Brussels, Belgium, 2010.

49. European Committee for Standardization. EN 933. Tests for Geometrical Properties of Aggregates. Part. 3: Determination of Particle Shape-Flakiness Index; European Committee for Standardization: Brussels, Belgium, 2012.

50. European Committee for Standardization. EN 12390-1 Testing h Rdened Concrete. Part. 1: Shape, Dimensions and Other Requirements for Specimens and Moulds; European Committee for Standardization: Brussels, Belgium, 2013.

51. European Committee for Standardization. EN 12390-3 Testing Hardened Concrete. Part. 3: Compressive Strength of Test. Specimens; European Committee for Standardization: Brussels, Belgium, 2020.

52. European Committee for Standardization. EN 12390-13 Testing Hardened Concrete. Part. 13: Determination of Secant Modulus of Elasticity in Compression; European Committee for Standardization: Brussels, Belgium, 2014.

53. García, C.T. Hormigón Reciclado de Aplicación Estructural: Durabilidad En Ambiente Marino y Comportamiento a Fatiga; Universty of Cantabria: Cantabria, Spain, 2012.

54. Weinstein, S.B.; Ebert, P.M. Data Transmission by Frequency-Division Multiplexing Using the Discrete Fourier Transform. IEEE Trans. Commun. Technol. 1971, 19, 628-634. [CrossRef]

55. Mathworks Fourier Series. n.d. Available online: https://uk.mathworks.com/help/curvefit/fourier.html (accessed on 5 May 2021).

56. Sainz-Aja, J.; Pombo, J.; Tholken, D.; Carrascal, I.; Polanco, J.; Ferreño, D.; Casado, J.; Diego, S.; Perez, A.; Filho, J.E.A.A.; et al. Dynamic Calibration of Slab Track Models for Railway Applications Using Full-Scale Testing. Comput. Struct. 2020, 228, 106180. [CrossRef]

57. Teychenné, D.C.; Franklin, R.E.; Erntroy, H.C. Design of Normal Concrete Mixes; BRE: Watford, North Dakota, 2010; Volume 331, p. 46.

58. Lantsoght, E.O.L.; Van Der Veen, C.; De Boer, A. Proposal for the Fatigue Strength of Concrete under Cycles of Compression. Constr. Build. Mater. 2016, 107, 138-156. [CrossRef]

59. Pacheco, J.; de Brito, J.; Chastre, C.; Evangelista, L. Experimental Investigation on the Variability of the Main Mechanical Properties of Concrete Produced with Coarse Recycled Concrete Aggregates. Constr. Build. Mater. 2019, 201, 110-120. [CrossRef]

60. Carloni, C.; Subramaniam, K.V. Investigation of Sub-Critical Fatigue Crack Growth in FRP/Concrete Cohesive Interface Using Digital Image Analysis. Compos. Part. B Eng. 2013, 51, 35-43. [CrossRef]

61. Thomas, C.; Sainz-Aja, J.; Setien, J.; Cimentada, A.; Polanco, J.A. Resonance Fatigue Testing on High-Strength Self-Compacting Concrete. J. Build. Eng. 2021, 35, 102057. [CrossRef] 
62. Skarżyński, Ł.; Tejchman, J. Experimental Investigations of Damage Evolution in Concrete during Bending by Continuous Micro-CT Scanning. Mater. Charact. 2019, 154, 40-52. [CrossRef]

63. Skarżyński, Ł.; Marzec, I.; Tejchman, J. Fracture Evolution in Concrete Compressive Fatigue Experiments Based on X-Ray Micro-CT Images. Int. J. Fatigue 2019, 122, 256-272. [CrossRef]

64. Vicente, M.A.; Mínguez, J.; González, D.C. Computed Tomography Scanning of the Internal Microstructure, Crack Mechanisms, and Structural Behavior of Fiber-Reinforced Concrete under Static and Cyclic Bending Tests. Int. J. Fatigue 2019, 121, 9-19. [CrossRef]

65. Sainz-Aja, J.; Carrascal, I.; Polanco, J.A.; Thomas, C. Fatigue Failure Micromechanisms in Ed Aggregate Mortar by MCT Analysis. J. Build. Eng. 2019, 101027. [CrossRef] 